\title{
Influence of Augmented Reality on the Achievement and Attitudes of Ambiguity Tolerant/Intolerant Students
}

\author{
Dina A. Ismaeel ${ }^{1} \&$ Ensaf N. Al Mulhim² \\ ${ }^{1}$ Faculty of Education, Helwan University, Cairo, Egypt \\ ${ }^{2}$ Faculty of Education, King Faisal University, Al-Ahsa, Saudi Arabia \\ Correspondence: Ensaf N. Al Mulhim, Faculty of Education, King Faisal University, Al-Ahsa, 31982, Saudi \\ Arabia.
}

Received: October 31, 2018

doi:10.5539/ies.v12n3p59
Accepted: December 5, 2018 Online Published: February 26, 2019

URL: https://doi.org/10.5539/ies.v12n3p59

\begin{abstract}
This paper aims to investigate the influence of augmented reality technology on the achievement and attitudes of student tolerance for ambiguity. Seventy-eight undergraduate students at King Faisal University participated in the experiment, in two groups according to their learning style (tolerant or intolerant of ambiguity). The findings revealed that augmented reality technology helps ambiguity-tolerant students improve achievement and form positive attitudes toward the use of augmented reality in learning more than it does those who are ambiguity intolerant. The study promotes taking account of students' learning styles and personal characteristics when designing interactive learning environments, to provide the best learning experience for their preferences.
\end{abstract}

Keywords: augmented reality, achievement, attitudes, learning styles, ambiguity tolerant, ambiguity intolerant

\section{Introduction}

Augmented reality (AR) technology is a new addition to the field of teaching and learning. This technology allows learners to examine all information in a stimulating and exciting setting that combines traditional learning content with the world's most innovative virtual objects (i.e., sound, images, and 2D or 3D animations). The core of a simulation strategy encourages discovery by the learners themselves, instead of through traditional text-based objects. Proponents of this new technology believe that it improves learners' perception and increases their interaction, thus the ease with which they visually understand information, leading to improvements in longer-term achievement. A study that Yoon and Wang (2014) conducted confirms this by showing that using AR in learning can improve student perceptions of information and increase the length of interaction with learning materials.

As part of the interest in designing interactive e-learning environments that take account of learners' traits, characteristics, and information-processing methods, investigating the role of student learning styles becomes crucial, especially in terms of achievement and attitudes. Tolerance and intolerance for ambiguity is one set of characteristics affecting how an individual learns and the methods for receiving and processing information.

Studying the suitability of this technology for students with different learning styles is preliminary to expanding the use of AR technology in educational settings at various levels. The perfect educational environment aligns teaching methods with student-learning styles, as students are the center of the entire learning process. Although AR is a modern and promising technology in the field of education, research focusing on the relationships between $\mathrm{AR}$ and different learning styles is seriously lacking.

The AR environment depends on the elements of discovery, surprise, and ambiguity, as students have no prior knowledge of the content that will appear. Therefore, studying the effects of utilizing AR technology with students from the perspective of ambiguity tolerance or intolerance is appropriate for determining the impact of the technology on achievement and attitudes. Ambiguity tolerance or intolerance is a learning style that may greatly affect the extent of a learner's desire to engage with and discover this environment, the main focus of the present study.

\section{Literature Review}

\subsection{Augmented Reality}

AR technology combines the real and the virtual, allows synchronous interactivity, and registers in three 
dimensions (Azuma, 1997). The core feature of AR is overlaying real and digital objects, in contrast to the virtual environment that completely obscures the reality and people around the user (Barfield, 2015; Ibáñez, Di Serio, Villarán, \& Kloos, 2014; Martín-Gutiérrez, Fabiani, Benesova, Meneses, \& Mora, 2015). AR technology implements virtual artistic images to enhance and facilitate interpretation of the real environment (Xue, 2017). El Sayed, Zayed, and Sharawy (2011) support this definition, stating that AR adds missing information to real-life scenes through enabling virtual objects. Unlike virtual reality (VR), AR does not require special, expensive, or complicated devices. It enables users to interact with the real environment around them face-to-face and not in a mediated way using avatars (Wojciechowski \& Cellary, 2013). Computerized simulation and application models implement this technology. AR has a wide range of applications in fields such as medicine, manufacturing and repair, annotation and visualization, robot path planning, entertainment, military aircraft (Azuma, 1997), engineering (Behzadan, Dong, \& Kamat, 2015), and education (Yen, Tsai, \& Wu, 2013). Within the education field, teaching with AR occurs in a number of subjects, including mathematics and science (Cascales-Martínez, Martínez-Segura, Pérez-López, \& Contero, 2017; Salmi, Thuneberg, \& Vainikainen, 2017), astronomy (Sirakaya, 2015), history (Kysela \& Štorková, 2015), and language (Küçük, Yılmaz, \& Yüksel, 2014a).

AR has transformed the education sector by creating a new and unique learning environment for students (Bacca, Baldiris, Fabregat, Graf, \& Kinshuk, 2014). The use of virtual environments motivates students to participate actively in lessons. This technology also enables more interactive learning sessions in schools. According to Radu (2014), AR can increase content understanding, improve the learning of spatial structures and functions, and enhance language associations, long-term memory, collaboration, motivation, and physical task performance. Similarly, Di Serio, Ibáñez, and Kloos (2013) and Ibáñez et al. (2014) believe that AR increases student motivation, engagement, and satisfaction with performing learning activities. The importance of AR may also arise from the possibility of engaging in dangerous, expensive, or impossible (Yuen, Yaoyuneyong, \& Johnson, 2011) teaching or experiments (Wojciechowski \& Cellary, 2013). AR also supports authentic learning (Wu, Lee, Chang, \& Liang, 2013), enables student-centered learning, and encourages constructive learning (Delello, 2014).

According to Dunleavy and Dede (2014), situated-learning and constructivist-learning theories support AR. According to situated-learning theory, learning occurs through interaction among all components of the setting where the learning takes place, including objects, places, and people. Drawing on this perspective, learning is a co-constructed and participatory process. In the AR learning context, learning is built through the interaction among students, their real surroundings, and the augmented objects.

Constructivism contends that the basis of learning is what individuals already know, and differs according to their developmental level, past experiences, social background, and interactions (Bruner, 1966). Using AR as a cognitive tool or pedagogical approach, where the learner is positioned physically and socially in a real-world context enriched by augmented objects, fits well with both situated-learning and constructivist-learning theories. Learners receive the necessary guidance and scaffolding, and facilitation of participatory and meta-cognitive learning processes, such as "authentic inquiry, active observation, peer coaching, reciprocal teaching and legitimate peripheral participation with multiple modes of representation" (Dunleavy \& Dede, 2014, p. 737).

\subsection{Augmented Reality and Student Achievement}

Many researchers believe that using AR technology improves student achievement (Akçayır \& Akçayır, 2017). According to Liou, Yang, Chen, and Tarng (2017), "learners can easily integrate virtual objects and real environments so as to decrease the mental load and improve their learning" (p. 118). Sirakaya and Kilic-Cakmak (2018a) conducted a study comparing the academic achievement of a control group (using a textbook only) and an experimental group (using AR technology) to learn about computer hardware components, ports, and assembly. The study results showed higher scores in the experimental group. Bal and Bicen (2016) examined the effectiveness of $A R$ and quick response (QR) code integration on student achievement by dividing students into a control group and an experimental group of 25 each. The data gathered from pre- and post-tests revealed that using AR and QR codes positively impacted students' academic achievement. Del Bosque, Martinez, and Torres (2015) aimed to decrease the high failure rate (reaching $70 \%$ ) of students in a core-structure programming subject at one college in Mexico. The students received an Android phone AR application to make their learning more dynamic and emotional and to help them grasp the logic of programming. The results of the study showed that AR technology decreased the failure rate in the subject by $50 \%$. A Taiwanese study by Chiang, Yang, and Hwang (2014), which applied an AR-based mobile system to a fourth-grade natural-science unit on aquatic animals and plants in a primary school, obtained similar results. The analysis of the pre- and post-tests demonstrated that the AR-based mobile learning approach was significantly valuable in enhancing student achievement. Likewise, Estapa and Nadolny (2015) assessed students' achievement and motivation during high-school mathematics classes. The researchers recruited 61 students and employed a survey and pre- and post-tests, and obtained 
evidence that the integration of AR into mathematics lessons increases student achievement and improves motivation. In their investigation of an AR application's effects on elementary-school students' spatial abilities and academic achievement, Gün and Atasoy (2017) employed mixed research methods. The experimental group used both AR and real objects to study a "geometric objects and measuring volume" topic, and the control group used only real objects. The data analysis showed significant improvement in the experimental group's academic achievement scores on the post-test.

These studies confirm that using AR technology greatly affects student performance and achievement by integrating virtual learning objects with real-world images in one simple and easy-to-use model, and attracting student attention and focusing it on the most important and fundamental elements of the learning content. In the AR environment, students become the center of learning and learn through what they do in a stimulating environment that increases their motivation to learn.

\subsection{Student Attitudes toward Augmented Reality}

According to Surakaya and Kiliç-Çakmak (2018b), exploring student attitudes toward AR is crucial to ensuring achievement of desired learning outcomes. In mixed-methods research, Gün and Atasoy (2017) designed a case study to collect qualitative data on students' and teachers' opinions about AR technology. The data analysis showed that using AR is enjoyable and helpful in visualizing abstract concepts. The students found that AR technology increased their interest in the course and caused their initial negative attitudes to become more positive. Wojciechowski and Cellary (2013) employed a Technology Acceptance Model (TAM) questionnaire to examine students' attitudes toward AR. Their experiment revealed that the use of AR is enjoyable and easy, encouraging students' willingness to use it for learning. An interesting study by Liou et al. (2017) compared AR and VR environments in terms of the acceptance of technology in an inquiry-based astronomy course. They employed a technology-acceptance questionnaire and showed that the AR group had significantly more positive perceptions in terms of their attitudes. Another experimental study by Cai, Chiang, Sun, Lin, and Lee (2017) evaluated students' satisfaction with and acceptance of the AR-based motion-sensing instruction method. The attitude questionnaire reflected positive findings in general, and the experimental group scored high on questions about the AR application. Küçük, Yılmaz, Baydaş, and Goktaş (2014b) examined achievement, attitudes, and cognitive-load level, and the correlations among these variables in students utilizing AR for learning English. Their study reported that students enjoyed learning English with AR and expressed positive attitudes toward the technology. The results also showed a positive correlation between the students' achievement level and their attitudes toward AR. A similar study was carried out in Taiwan by Wang (2017), using an AR system to support students in acquiring Chinese writing skills. A total of 30 high-school students participated in the study. The experimental group used both AR-based and traditional materials, while the control group was not allowed to use any AR-based materials to participate in the writing activities. The experimental group perceived AR as a helpful tool to support their Chinese writing skills, especially the low achievers, who reported that the AR system helped them in writing their very first paragraph.

This review of previous studies shows that students have positive attitudes toward AR technology in general. Additionally, students find AR tools enjoyable, motivating, and easy to use. These results are not surprising, because students usually have positive attitudes toward modern technologies and mobile applications, such as smartphones and tablets (Al Subeh, Alali, \& Awaisu, 2017; Demir \& Akpinar, 2018; Zhu, Yang, MacLeod, Shi, \& $\mathrm{Wu}, 2018)$. However, this interest in technology may vary according to students' varying learning styles, which play a key role in shaping the way they process and receive information, thus significantly affecting development of attitudes toward the way they learn.

\subsection{Ambiguity Tolerance/Intolerance}

The literature emphasizes the importance of studying student learning styles in order to understand how students learn in, perform in, react to, succeed in, and respond to the learning environment (Chiang, 2016; Tayebinik \& Puteh, 2013; Shahsavar \& Hoon, 2011). Learning styles are stable indicators of different learner characteristics, including their cognitive, affective, intellectual, and psychological behaviors (Chiang, 2016; Shahsavar \& Hoon, 2011). Thus, teachers should develop an awareness of these personal characteristics to help them design instruction to support the learning preferences of their students (Saeed, Yang, \& Sinnappan, 2009).

One characterization of learning styles is tolerance or intolerance for ambiguity. Ambiguity tolerance/intolerance is a psychological construct that defines an individual's relationship with ambiguous stimuli or events. Ambiguity tolerance interprets ambiguous stimuli in a neutral and desirable way. In contrast, ambiguity-intolerant individuals perceive those same stimuli as a threat (Budner, 1962), finding the absence of information frustrating, stressful, and risky, making them more likely to escape, avoid, reject, and delay reaching judgments. On the other hand, 
ambiguity-tolerant individuals are more likely to perform well and enjoy encountering a complex, innovative, and uncertain situation (Chiang, 2016; Tayebinik \& Puteh, 2013; Owen \& Sweeney, 2002).

Much research literature compares students who are ambiguity tolerant or intolerant in terms of their language learning, performance, achievement, participation, attitudes, and communicative competence (Chiang, 2016; Atamanova \& Bogomaz, 2014; Shahsavar \& Hoon, 2011; Owen \& Sweeney, 2002). The results of these studies found no significant differences between students tolerant or intolerant of ambiguity. However, learning styles in the technology-based learning environment have not been widely examined. According to Saeed et al. (2009), "there is a need to understand the relationship between students' learning styles and their preferences for instructional strategies, including the use of emerging web technologies" (p. 98). Contrary to the results of the above-mentioned studies, results of studies comparing ambiguity tolerance and intolerance in e-learning environments mostly favor ambiguity-tolerant students (Tayebinik \& Puteh, 2013; Saeed et al., 2009). These studies assert that teachers should offer more support for ambiguity-intolerant students who may use different learning strategies to cope with difficulties.

Edison and Geissler (2003) mention that "technology is often complex, contradictory and ambiguous" (p. 141). Thus, a clear relationship exists between ambiguity tolerance or intolerance and the use of modern technology in learning. Adding the virtual elements of AR to such traditional tools as textbooks may lead to more complexity, frustration, and ambiguity for some learners (Chu, 2014). Even though nowadays technology is desirable and very interesting for student learning (Zhu et al., 2018), learners not ready to deal with these modern tools due to their personal characteristics represent an area needing more investigation.

\section{Research Questions and Hypotheses}

The current research aims to identify the impact of augmented reality technology on the achievement and attitudes of ambiguity tolerant or intolerant students. The research focuses on the following questions:

- Does learning using AR technology improve ambiguity tolerant/intolerant students' achievement?

- Does learning using AR technology help ambiguity tolerant/intolerant students create positive attitudes?

To answer these questions, the following hypotheses must be examined:

1) There are no statistically significant differences at the level (0.05) among the average achievement scores of students tolerant or intolerant of ambiguity using AR technology in a "Components of the Computer" unit.

2) There are no statistically significant differences at the level (0.05) among ambiguity tolerant or intolerant students' average scores on the attitudes-toward-learning scale after a "Components of Computer" unit using AR technology.

\section{Experiment}

\subsection{Methodology}

This research applies the experimental approach to determine the influence of AR technology on the achievement and attitudes of ambiguity tolerant or intolerant students.

\subsection{Participants}

Participants in the experiment were 78 students enrolled in an undergraduate course called "Computer Applications in Education" in the College of Education at King Faisal University during the first semester of the 2017-2018 school year. They were divided into two groups of 39 each, according to whether they were tolerant or intolerant of ambiguity.

\subsection{Independent Variables}

The current research consists of two independent variables:

- The AR technology variable

- The ambiguity tolerant/intolerant learning style variable

The following sections review the two variables.

\subsubsection{Augmented Reality Technology Variable}

Two researchers designed two experimental treatments in light of the patterns of the two independent experimental variables. The first was for students with ambiguity tolerance, who studied using the AR system. The second treatment was for students with ambiguity intolerance, who studied using AR as well. All factors of the experimental controls were considered to ensure the validity of the content of the experimental treatments, namely, 
the design of the educational handbooks about the components of the computer using the AR technology.

The researchers relied on Branch's (2009) Analysis, Design, Development, Implementation, and Evaluation (ADDIED) Model for educational design in constructing the experimental treatments, following the model's five procedural steps.

- The analysis stage involved:

- Setting the overall goal of learning by measuring the impact of using AR technology on the academic achievement of ambiguity tolerant or intolerant students and their attitudes toward learning using this technique;

- Identifying the characteristics of the learners by selecting third-level students in the College of Education enrolled in an Introduction to Computers course, as they were approximately at the same educational level and age (age 17-18 years old), not familiar with the educational content the AR technology would provide, and possessing basic skills needed for dealing with computers and the Internet in general;

- Analyzing learning tasks and needs by developing educational handbooks using AR technology (the first independent variable) to measure their impact on ambiguity tolerant or intolerant students (the second independent variable), and improvement of their achievement and attitudes toward the use of this technology in learning;

- Analyzing the learning environment by requiring the availability of smartphones or tablets connected to the Internet in the application of the study experiment.

- The design stage involved:

- Setting the behavioral objectives by choosing the subject of computer components as the content for the educational handbooks the AR technology (augmented handbook) produced, thus identifying the behavioral objectives for this subject; preparing a preliminary list of these objectives and presenting them to a group of education technology judges to seek their opinions on the validity of the objectives and the precision of their formulation; receiving the judges' unanimous agreement on the reliability of the objectives (98\%) and their recommendations for some modifications to the formulation; making these changes and preparing the list of objectives in its final form;

- Designing the augmented handbook by identifying and collecting images, drawings, and videos to use in designing the AR technology; designing the educational augmented handbooks and identifying the areas to correlate the information in the handbooks to the collected multimedia elements; a group of judges reviewing the handbooks in their preliminary form and sharing their observations; making some changes and preparing the handbooks in their final form.

- The development stage involved:

- Producing the multimedia elements by collecting the tools available and appropriate for the objectives of the subject content, including the texts, images, and drawings; producing unavailable tools; using many applications in this stage, including Microsoft PhotoDraw, Adobe Photoshop 8 for image and graphics production, Microsoft Word for text production, and Powtoon for producing the animated motion pictures used in the production of the AR technology;

- Producing the augmented handbook by using the Aurasma mobile application, linking multimedia items to the educational handbook pages in the areas pre-identified for the production of the handbooks (experimental materials) into their final form.

- Implementation stage involved testing the research tools on a sample of 20 randomly selected female students in the College of Education, King Faisal University. The researchers ensured their lack of prior knowledge, so the survey sample reflected the same characteristics as the original sample community, and likewise were divided into 2 groups (10 female students each) according to their ambiguity tolerance or intolerance. The researchers administered measuring tools and experimental treatment materials to ascertain their clarity, to check their suitability to the students' level, to calculate the reliability and validity of the measuring instruments, and to identify any difficulties the researchers might face during the implementation of the actual experiment, as well as to set the time for implementing the experiment.

- Evaluation stage involved the structural evaluation of all stages of designing and producing the experimental treatments, to ensure the integrity of the previous stages and to determine their validity; taking account of the views and comments from the pilot experiment; and declaring the treatments ready to apply to the actual research sample. 


\subsubsection{Ambiguity Tolerant/Intolerant Learning Style Variable}

Researchers administered the Budner (1962) Tolerance of Ambiguity Scale to classify the research sample according to this learning style, in terms of learners' ability to accept complex and ambiguous situations and stimuli. The scale consists of 16 items, with 8 items of positive value and 8 items of negative value. Modifications to match the nature of the current research were made in the formulation of some sentences of the scale.

A seven-point Likert scale, used to determine the response probabilities for each of the scale items, varied in intensity from full consent to complete opposition. Accordingly, the range of responses was 1-7, as follows:

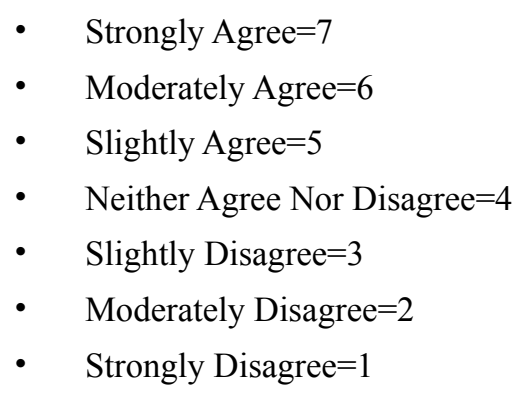

To score the instrument, the positive items received the following values according to how positive they were $(7,6,5,4,3,2,1)$ where 7 represents "most positive" and 1 represents "least positive"; the order was reversed with the negative items, which received the values $(1,2,3,4,5,6,7)$.

On this scale, the maximum score a learner could obtain was 112, and the lowest score was 16. Calculating the general averages of the total scores of the participants enabled distinguishing between ambiguity-tolerant and ambiguity-intolerant learners. An ambiguity-intolerant person obtains a total score higher than the general average, while an ambiguity-tolerant person receives a total score lower than the general average of the research sample.

Budner (1962) reported test reliability of 0.85 , a high value indicating that the scale is highly reliable.

\subsection{Dependent Variables}

\subsubsection{Achievement Test}

Researchers prepared a closed-ended test to measure the cognitive aspects (achievement) of the concepts related to the subject of Components of the Computer was included in the augmented handbooks (experimental materials) for the students in the experimental groups. The test items were formulated as objective questions. The test consisted of 90 multiple-choice questions. The distribution of scores for the test items varied between 1 and 2 points, so that the total score on the test was 100 points.

To find the validity of the achievement test, a group of judges in the field of educational technology reviewed it in its initial form and expressed their opinions about the test, in terms of its coverage of the educational goals, its relevance to the content, and the relevance and precision of the test items. The judges unanimously agreed to grant the test more than $94 \%$. They also recommended amending the wording of some items. The amendments were made, and the test became applicable for the participants of the pilot experiment to calculate the statistical validity of the test.

In order to calculate the reliability of the test, the pilot group of 20 female students took the test. Using split-half reliability on the test items for individual questions and even questions, reliability was calculated using the Spearman-Brown equation and the correlation coefficient between the two parts. The reliability coefficient was (0.84), an acceptable value for exam reliability. The average response time for the test was calculated at 90 minutes.

\subsubsection{Attitudes}

The scale that measures student attitudes (Küçük et al., 2014b) toward AR was administered in order to collect data on the attitudes of the participants toward the use of AR technology in learning, and to realize its impact on the presentation of the subject to be learned. In its final form, the scale comprised 15 items divided into 3 categories:

- Use satisfaction, consisting of 7 positive items;

- Use anxiety, consisting of 6 negative items;

- Use willingness, consisting of 2 positive items.

A 5-point Likert scale was used to determine the response possibilities for each scale item, varying in intensity 
from strong agreement to strong disagreement, with responses ranging from 1-5, as follows:

- $\quad$ Strongly agree $=5$

- Agree $=4$

- Neither Agree Nor Disagree $=3$

- $\quad$ Disagree=2

- $\quad$ Strongly Disagree=1

To score the instrument, the positive items received the following values according to the degree of how positive they are $(5,4,3,2,1)$ where 5 represents "most positive" and 1 represents "least positive"; the order is reversed with the negative items that received values $(1,2,3,4,5)$.

On this scale, the maximum score a learner can obtain on the scale is 75 , and the lowest score is 15 . Some modifications were made while drafting some of the scale clauses to suit the nature of the current research. The validity of the scale was calculated by presenting it to a group of judges in the field of educational psychology and psychological measurement, to survey their views on the appropriateness of the wording of the scale items and suitability for the general purpose of the scale. The judges recommended changes to certain items, which were made and finalized.

As for the reliability of the scale, as Küçük et al. (2014b) point out, the scale is 0.83 reliable. The present researchers calculated the scale reliability by applying it to the female students in the pilot sample of the study. Using Spearman's coefficient to calculate the reliability of the scale, he result was 0.93 , a high result indicating the high reliability of the scale.

\subsection{Experimental Procedure and Data Collection}

- The scale of ambiguity tolerance/intolerance was administered to 78 students in the third level of a Computer Applications course at the College of Education to classify the students according to whether they were ambiguity tolerant (39) or ambiguity intolerant (39).

- The achievement pretest was administered to the experimental groups to ensure the equivalence of the two groups.

- An introductory meeting was held to explain how to use the handbooks created using AR technology, how to interact with its digital content, how to download the Aurasma application on students' smartphones, how to $\log$ into the accounts prepared for the students by the researchers, and how to use the application.

- The experimental materials - represented here in the augmented handbooks - were administered to the groups.

- The application of the experiment took about four weeks, starting from October 15, 2017, and continuing until November 14, 2017.

- The achievement post-test and the attitude scale were applied to both of the experimental groups.

- After finishing the administration of the experiment, the researchers recorded the scores on the achievement test and attitude scale to prepare to perform statistical analyses.

- Data processing and statistical analyses were performed using SPSS 22 to test the research hypotheses, using the independent samples t-test to measure the statistical differences between the average scores of the two experimental groups on the achievement test and on the attitude-toward-AR scale.

The following section presents the results of the statistical data analysis.

\section{Results and Discussion}

\subsection{Homogeneity between Experimental Groups}

The homogeneity between the two experimental groups was calculated using the independent samples t-test to identify any significant differences between the two groups in the achievement pretest scores. Table 1 shows the means and standard deviations (SDs) of the ambiguity-tolerant group $(\mathrm{M}=8.154, \mathrm{SD}=2.266, \mathrm{~N}=39)$, and the ambiguity-intolerant group ( $\mathrm{M}=7.462, \mathrm{SD}=2.674, \mathrm{~N}=39)$. 
Table 1. T-test for the research groups on the achievement pre-test

\begin{tabular}{ccccccc}
\hline Group & $\mathrm{N}$ & Mean & SD & Df & T & Sig. \\
\hline Ambiguity Tolerant & 39 & 8.154 & 2.266 & \multirow{2}{*}{76} & 1.234 & 0.221 \\
Ambiguity Intolerant & 39 & 7.462 & 2.674 & & & \\
\hline
\end{tabular}

The t-test test revealed that there were no statistically significant differences between the two experimental groups before conducting the experiment $(\mathrm{t}=1.234, \mathrm{p}>0.05)$, thus there was homogeneity between the two groups.

\subsection{Achievement}

The independent samples t-test was used to identify any significant differences between the two experimental groups' achievement scores. Table 2 shows the means and SDs of the ambiguity-tolerant group $(\mathrm{M}=86.28$, $\mathrm{SD}=6.052, \mathrm{~N}=39)$ and the ambiguity-intolerant group $(\mathrm{M}=82.18, \mathrm{SD}=10.432, \mathrm{~N}=39)$.

Table 2. T-test for the research groups on the achievement post-test scores

\begin{tabular}{ccccccc}
\hline Group & $\mathrm{N}$ & Mean & SD & Df & T & Sig. \\
\hline Ambiguity Tolerant & 39 & 86.28 & 6.052 & \multirow{2}{*}{76} & \multirow{2}{*}{2.124} & \multirow{2}{*}{0.037} \\
Ambiguity Intolerant & 39 & 82.18 & 10.432 & & & \\
\hline
\end{tabular}

The results of the t-test showed that there were statistically significant differences between the average scores of the students from the two experimental groups on the achievement post-test for the ambiguity-tolerant group $(\mathrm{t}=2.124, \mathrm{p}<0.05)$, with a highest mean value of 86.28 . Thus, the first hypothesis was rejected.

This result may be due to the fact that with its new stimuli that combine reality with virtual elements, AR technology suited the nature and characteristics of the ambiguity-tolerant students. These students are capable of accepting the content in its new form, and they have a great interest in learning in an enjoyable way with new stimuli, as pointed out by Chiang (2016), Saeed et al., (2009), Tayebinik and Puteh (2003), and Owen and Sweeney (2002).

Additionally, AR technology has the ability to focus the learners' attention on the most important information of the lesson, using the power of multimedia elements that improve the learning process. AR provides an excellent opportunity to engage learners in the learning process for longer periods of time, improve their interaction, and encourage self-learning, all of which have a positive influence on improving the learner's level of achievement.

Moreover, the situated-learning and constructivist-learning theories support the use of AR in helping learners build their learning through interactions with reality and virtualization, which improve learning achievement (Dunleavy \& Dede, 2014). This result agrees with the research of Sirakaya and Kilic-Cakmak (2018a), Liou et al. (2017), Gün and Atasoy (2017), Akçayır and Akçayır (2017), Bal and Bicen (2016), Del Bosque et al. (2015), Estapa and Nadolny (2015), and Chiang et al. (2014), all of whom emphasize the effectiveness of using AR to increase students' ability to achieve and participate in learning activities while making learning more dynamic and interactive.

\subsection{Attitudes}

Researchers used the independent samples t-test to identify any significant differences between the two groups on the scale measuring attitudes toward the use of AR technology in education. Table 3 shows the means and SDs of the ambiguity-tolerant group $(\mathrm{M}=59.97, \mathrm{SD}=7.439, \mathrm{~N}=39)$ and the ambiguity-intolerant group $(\mathrm{M}=54.41$, $\mathrm{SD}=8.559, \mathrm{~N}=39$ ).

Table 3. T-test for the research groups on the attitudes questionnaire scores

\begin{tabular}{ccccccc}
\hline Group & $\mathrm{N}$ & Mean & SD & Df & T & Sig. \\
\hline Ambiguity Tolerant & 39 & 59.97 & 7.439 & \multirow{2}{*}{76} & \multirow{2}{*}{3.064} & 0.003 \\
Ambiguity Intolerant & 39 & 54.41 & 8.559 & & & \\
\hline
\end{tabular}

The results of the t-test analysis showed statistically significant differences between the mean scores of the students in the two groups on the attitude toward AR scale $(t=3.064, p<0.05)$, with the ambiguity-tolerant group having the highest mean value (59.97). Thus, the second hypothesis was rejected. 
This finding may be interpreted in terms of the nature of ambiguity-tolerant learners, who prefer to confront ambiguous, complex, and new situations and stimuli. AR often provides a high degree of ambiguity that motivates learners to discover new knowledge through interaction with the AR components. This makes using this technology more fun and attractive, which helps to create positive attitudes toward learning when the technology is well aligned with their personal characteristics.

On the other hand, learners who are ambiguity-intolerant find AR complex, confusing, and frustrating, especially when they are not familiar with using it to learn. According to Chu (2014), learners may feel frustrated and disappointed when they face complex learning resources that mix real and digital objects.

The research of Sirakaya and Kilic-Cakmak (2018a), Gün and Atasoy (2017), Liou et al. (2017), Cai et al. (2017), Wang (2017), Küçük et al. (2014a), Wojciechowski and Cellary (2013) supports this finding. They all suggest that the use of AR increases students' motivation and enjoyment and thus holds their attention for learning, which clearly reflects the positive effects on the development of their attitudes toward the use of AR in education.

\section{Conclusion}

The current study aimed to examine the influence of AR technology on ambiguity tolerant/intolerant students' achievement and attitudes. The literature asserts that learning about students' personality traits and learning styles is very helpful for teacher predictions of the best way for students to perform and achieve, enabling teachers to facilitate the most encouraging environment. However, there is a lack of studies in the literature exploring the effects of this learning style on the use of AR technology. The results of this study have shown that AR had more positive effects on ambiguity-tolerant students' achievement and attitudes than on those who are ambiguity intolerant.

Ambiguity-tolerant students are more flexible and capable of coping with cognitive complexity (Edison \& Geissler, 2003). They are more eager to deal with the latest complex, contradictory, and ambiguous technology and more able to control their learning process and make appropriate decisions. As a result, their performance is expected to be higher, which in turn improves achievement and their attitudes toward this way of learning. On the other hand, for ambiguity-intolerant students, using modern technology may be frustrating and full of pressure and discomfort because of the novelty of the educational approach. This problem can become worse when a technical or learning problem arises while using any new technology. Thus, those students need more support from their teachers to overcome these problems and difficulties in their learning and become more familiar with AR.

The positive influence of AR as a technology may come from its novelty and fascinating interface. Therefore, it may be that when students become accustomed to AR, this influence may decrease. Thus, the researchers recommend doing a follow-up study after a period of time to test the long-term influence on student achievement and attitudes. AR technology designers are also urged to develop new learning strategies emphasizing interactive 3D content. More studies examining AR technology's influence on other learning styles, such as field-dependent or field-independent learners and impulsive or reflective learners, are also recommended.

\section{References}

Akçayır, M., \& Akçayır, G. (2017). Advantages and challenges associated with augmented reality for education: A systematic review of the literature. Educational Research Review, 20, 1-11. https://doi.org/10.1016/j.edurev.2016.11.002

Al Subeh, Z., Alali, F., \& Awaisu, A. (2017). Attitudes towards using smart devices and medical applications among pharmacy students, preceptors and faculty members in Jordan. Pharmacy Education, 17, 308-315.

Atamanova, I., \& Bogomaz, S. (2014). Ambiguity tolerance as a psychological factor of foreign language communicative competence development. Procedia-Social and Behavioral Sciences, 154, 345-352. https://doi.org/10.1016/j.sbspro.2014.10.161

Azuma, R. T. (1997). A survey of augmented reality. Presence: Teleoperators \& Virtual Environments, 6(4), 355-385. https://doi.org/10.1162/pres.1997.6.4.355

Bacca, J., Baldiris, S., Fabregat, R., Graf, S., \& Kinshuk. (2014). Augmented reality trends in education: A systematic review of research and applications. Educational Technology \& Society, 17(4), 133-149.

Bal, E., \& Bicen, H. (2016). Computer hardware course application through augmented reality and QR code integration: Achievement levels and views of students. Procedia Computer Science, 102, 267-272. https://doi.org/10.1016/j.procs.2016.09.400

Barfield, W. (2015). Fundamentals of wearable computers and augmented reality. Boca Raton: CRC Press. https://doi.org/10.1201/b18703 
Behzadan, A. H., Dong, S., \& Kamat, V. R. (2015). Augmented reality visualization: A review of civil infrastructure system applications. Advanced Engineering Informatics, 29(2), 252-267. https://doi.org/10.1016/j.aei.2015.03.005

Branch, B. M. (2009). Instructional design: The ADDIE approach. New York: Springer Science + Business Mediaa, LLC. https://doi.org/10.1007/978-0-387-09506-6

Bruner, J. S. (1966). Toward a theory of instruction. Belknap: Cambridge, MA. https://doi.org/10.1177/019263656605030929

Budner, S. (1962). Intolerance of ambiguity as a personality variable1. Journal of Personality, 30(1), 29-50. https://doi.org/10.1111/j.1467-6494.1962.tb02303.x

Cai, S., Chiang, F. K., Sun, Y., Lin, C., \& Lee, J. J. (2017). Applications of augmented reality-based natural interactive learning in magnetic field instruction. Interactive Learning Environments, 25(6), 778-791. https://doi.org/10.1080/10494820.2016.1181094

Cascales-Martínez, A., Martínez-Segura, M. J., Pérez-López, D., \& Contero, M. (2017). Using an augmented reality enhanced tabletop system to promote learning of mathematics: A case study with students with special educational needs. EURASIA Journal of Mathematics, Science and Technology Education, 13(2), 355-380. https://doi.org/10.12973/eurasia.2017.00621a

Chiang, H. H. (2016). A study of interactions among ambiguity tolerance, classroom work styles, and English proficiency. English Language Teaching, 9(6), 61-75. https://doi.org/10.5539/elt.v9n6p61

Chiang, T.-H.-C., Yang, S.-J.-H., \& Hwang, G.-J. (2014). An augmented reality-based mobile learning system to improve students' learning achievements and motivations in natural science inquiry activities. Educational Technology \& Society, 17(4), 352-365.

Chu, H. C. (2014). Potential negative effects of mobile learning on students' learning achievement and cognitive load - A format assessment perspective. Educational Technology \& Society, 17(1), 332-344.

Del Bosque, L., Martinez, R., \& Torres, J. L. (2015). Decreasing failure in programming subject with augmented reality tool. Procedia Computer Science, 75, 221-225. https://doi.org/10.1016/j.procs.2015.12.241

Delello, J. A. (2014). Insights from pre-service teachers using science-based augmented reality. Journal of Computers in Education, 1(4), 295-311. https://doi.org/10.1007/s40692-014-0021-y

Demir, K. \& Akpinar, E. (2018). The effect of mobile learning applications on students' academic achievement and attitudes toward mobile learning. Malaysian Online Journal of Educational Technology, 6(2), 48-59. https://doi.org/10.17220/mojet.2018.02.004

Di Serio, Á., Ibáñez, M. B., \& Kloos, C. D. (2013). Impact of an augmented reality system on students' motivation for a visual art course. Computers \& Education, 68, 586-596. https://doi.org/10.1016/j.compedu.2012.03.002

Dunleavy, M., \& Dede, C. (2014). Augmented reality teaching and learning. In J. Spector, M. Merrill, J. Elen, \& M. Bishop (Eds.), Handbook of Research on Educational Communications and Technology (pp. 735-745). New York: Springer. https://doi.org/10.1007/978-1-4614-3185-5_59

Edison, S. W., \& Geissler, G. L. (2003). Measuring attitudes towards general technology: Antecedents, hypotheses and scale development. Journal of Targeting, Measurement and Analysis for Marketing, 12(2), 137-156. https://doi.org/10.1057/palgrave.jt.5740104

El Sayed, N. E., Zayed, H. H., \& Sharawy, M. I. (2011). ARSC: Augmented reality student card an augmented reality solution for the education field. Computers \& Education, 56(4), 1045-1061. https://doi.org/10.1016/j.compedu.2010.10.019

Estapa, A., \& Nadolny, L. (2015). The effect of an augmented reality enhanced mathematics lesson on student achievement and motivation. Journal of STEM Education, 16(3), 40-48.

Gün, E. T., \& Atasoy, B. (2017). The effects of augmented reality on elementary school students' spatial ability and academic achievement. Egggitim ve Bilim, 42(191), 31-51. https://doi.org/10.15390/eb.2017.7140

Ibáñez, M. B., Di Serio, Á., Villarán, D., \& Kloos, C. D. (2014). Experimenting with electromagnetism using augmented reality: Impact on flow student experience and educational effectiveness. Computers \& Education, 71, 1-13. https://doi.org/10.1016/j.compedu.2013.09.004

Küçük, S., Yılmaz, R. M., Baydaş, O. \& Goktaş, Y. (2014b). Augmented Reality Applications Attitude Scale in 
Secondary Schools: Validity and Reliability Study. Education and Science, 39(176), 383-392. https://doi.org/10.15390/eb.2014.3590

Küçük, S., Yılmaz, R., \& Yüksel, G. (2014a). Augmented reality for learning English: Achievement, attitude and cognitive load levels of students. Education and Science, 39(176), 393-404. https://doi.org/10.15390/eb.2014.3595

Kysela, J., \& Štorková, P. (2015). Using augmented reality as a medium for teaching history and tourism. Procedia-Social and Behavioral Sciences, 174, 926-931. https://doi.org/10.1016/j.sbspro.2015.01.713

Liou, H.-H., Yang, S. J. H., Chen, S. Y., \& Tarng, W. (2017). The influences of the 2D image-based augmented reality and virtual reality on student learning. Educational Technology \& Society, 20(3), 110-121.

Martín-Gutiérrez, J., Fabiani, P., Benesova, W., Meneses, M. D., \& Mora, C. E. (2015). Augmented reality to promote collaborative and autonomous learning in higher education. Computers in Human Behavior, 51(Part B), 752-761. https://doi.org/10.1016/j.chb.2014.11.093

Owen, W. N., \& Sweeney, R. B. (2002). Ambiguity tolerance, performance, learning, and satisfaction: A research direction. Paper presented at ISECON 2002, San Antonio, TX.

Radu, I. (2014). Augmented reality in education: A meta-review and cross-media analysis. Personal and Ubiquitous Computing, 18(6), 1533-1543. https://doi.org/10.1007/s00779-013-0747-y

Saeed, N., Yang, Y., \& Sinnappan, S. (2009). Emerging web technologies in higher education: A case of incorporating blogs, podcasts and social bookmarks in a web programming course based on students' learning styles and technology preferences. Educational Technology \& Society, 12(4), 98-109.

Salmi, H., Thuneberg, H., \& Vainikainen, M. P. (2017). Making the invisible observable by Augmented Reality in informal science education context. International Journal of Science Education, Part B, 7(3), 253-268. https://doi.org/10.1080/21548455.2016.1254358

Shahsavar, Z., \& Hoon, T. B. (2011). Does cognitive style affect bloggers' attitude in an online learning environment? GEMA Online ${ }^{\circledR}$ Journal of Language Studies, 11(1), 159-171.

Sirakaya, M. (2015). Effects of augmented reality applications on students' achievement, misconceptions and course engagement (Unpublished doctoral dissertation, Gazi University, Turkey).

Sirakaya, M., \& Kilic-Cakmak, E. (2018a). Effects of augmented reality on student achievement and self-efficacy in vocational education and training. International Journal for Research in Vocational Education and Training, 5(1), 1-18.

Sırakaya, M., \& Kiliç-Çakmak, E. (2018b). Investigating student attitudes toward augmented reality. Malaysian Online Journal of Educational Technology, 6(1), 30-44.

Tayebinik, M., \& Puteh, M. (2013). The role of ambiguity tolerance in participation in online EFL courses. British Journal of Educational Technology, 44(6), E207-E208. https://doi.org/10.1111/bjet.12087

Wang, Y. H. (2017). Exploring the effectiveness of integrating augmented reality-based materials to support writing activities. Computers \& Education, 113, 162-176. https://doi.org/10.1016/j.compedu.2017.04.013

Wojciechowski, R., \& Cellary, W. (2013). Evaluation of learners' attitude toward learning in ARIES augmented reality environments. Computers \& Education, 68, 570-585. https://doi.org/10.1016/j.compedu.2013.02.014

Wu, H. K., Lee, S. W. Y., Chang, H. Y., \& Liang, J. C. (2013). Current status, opportunities and challenges of augmented reality in education. Computers \& Education, 62, 41-49. https://doi.org/10.1016/j.compedu.2012.10.024

Xue, H. (2017). Augmented reality application for training in maritime operations. A proof of concept AR application developed for Microsoft HoloLens (Master's thesis, UiT Norges Aarktiske Uuniversitet).

Yen, J.-C., Tsai, C.-H., \& Wu, M. (2013). Augmented reality in the higher education: Students' science concept learning and academic achievement in astronomy. Procedia -Social and Behavioral Sciences, 103, 165-173. https://doi.org/10.1016/j.sbspro.2013.10.322

Yoon, S. A., \& Wang, J. (2014). Making the invisible visible in science museums through augmented reality devices. TechTrends, 58(1), 49-55. https://doi.org/10.1007/s11528-013-0720-7

Yuen, S., Yaoyuneyong, G., \& Johnson, E. (2011). Augmented reality: An overview and five directions for AR in education. Journal of Educational Technology Development and Exchange, 4(1), 119-140. https://doi.org/10.18785/jetde.0401.10 
Zhu, S., Yang, H. H., MacLeod, J., Shi, Y., \& Wu, D. (2018). Parents' and students' attitudes toward tablet integration in schools. The International Review of Research in Open and Distributed Learning, 19(4), 221-241. https://doi.org/10.19173/irrodl.v19i4.2970

\section{Copyrights}

Copyright for this article is retained by the author(s), with first publication rights granted to the journal.

This is an open-access article distributed under the terms and conditions of the Creative Commons Attribution license (http://creativecommons.org/licenses/by/4.0/). 